\title{
A SELECTIVE AND SENSITIVE METHOD DEVELOPMENT AND VALIDATION BY LC-MS/MS APPROACH FOR TRACE LEVEL QUANTIFICATION OF POTENTIAL GENOTOXIC IMPURITY OF BOC EPOXIDE IN ATAZANAVIR SULPHATE DRUG SUBSTANCE
}

\author{
NELATURI SUBBAIAH'* , GOPIREDDY VENKATA SUBBA REDDY² \\ ${ }^{1}$ Department of Chemistry, S. R. N. B. Degree and P. G. College, Badvel, Kadapa, Andhra Pradesh, 516 227, India, ${ }^{2}$ Department of Chemistry, \\ JNTUA College of Engineering, Pulivendula, Kadapa, Andhra Pradesh, 560390, India \\ Email: subbareddy083@gmail.com \\ Received: 25 Mar 2017 Revised and Accepted: 13 Jul 2017
}

\begin{abstract}
Objective: To develop and validate a selective, sensitive, rapid and accurate method using LC-MS/MS technique to achieve efficient separation between active pharmaceutical ingredient (Atazanavir sulphate) and genotoxic impurity (BOC epoxide).

Methods: The quantification was carried out using the column puro sphere star RP 18 e (length $150 \mathrm{~mm}$, internal diameter $4.6 \mathrm{~mm}$, particle size 3.0 $\mu \mathrm{m}$ ) with electrospray ionization in multiple reaction monitoring (MRM) detection mode. Eluent-A was $0.1 \%$ formic acid in water and eluent-B was $0.1 \%$ formic acid and $0.1 \%$ ammonium hydroxide solution $(25 \%)$ in acetonitrile. The isocratic mode of elution was carried out for the elution of impurity with the shorter run time of $6 \mathrm{~min}$. The flow rate was $1.0 \mathrm{ml} / \mathrm{min}$ and column oven temperature was maintained $25^{\circ} \mathrm{C}$.
\end{abstract}

Results: The method was validated as per ICH guidelines and arrived the limit of detection and limit of quantification for the potential genotoxic impurity and found to be $0.2 \mathrm{ppm}$ and $0.5 \mathrm{ppm}$. The developed method was found linear in the concentration range of $0.5 \mathrm{ppm}$ to $6 \mathrm{ppm}$ and accuracy results were within the range.

Conclusion: The developed short span method found to be selective, sensitive, precise and accurate for the quantification of the BOC epoxide genotoxic impurity in atazanavir sulphate drug substance.

Keywords: Atazanavir sulphate, LC-MS/MS, Genotoxic impurity, Multiple reaction monitoring (MRM), DEREK nexus software

(c) 2017 The Authors. Published by Innovare Academic Sciences Pvt Ltd. This is an open access article under the CC BY license (http://creativecommons.org/licenses/by/4.0/) DOI: http://dx.doi.org/10.22159/ijpps.2017v9i9.20248

\section{INTRODUCTION}

Atazanavir sulphate (fig. 1a) is an HIV-1 protease inhibitor (PI) and sold under the trade name Reyataz. The chemical name of atazanavir is [methyl N-[(1S)-1-\{[(2S, 3S)-3-hydroxy-4-[(2S)-2-[(methoxycarbonyl) amino]-3,3-dimethyl-N'-\{[4-(pyridine-2-yl) phenyl] methyl $\}$ butanehydrazido]-1-phenylbutan-2-yl]carbomoyl\}-2,2-dimethyl-propyl] carbamate]. Its molecular formula is C38H52N6O7. H2SO4, which corresponds to a molecular weight of 802.9 (with sulphuric acid salt). Tert-butyl 1-(oxiran-2-yl)-2-phynyl-ethyl carbamate (BOC epoxide) (fig. 1b) chemical is used in atazanavir sulphate process at early stage. Since there is a structural alert, it is essential to control and prove that this material is not carried to the final stage. The literature survey revealed that the determination of process related and degradation impurities in atazanavir sulphate and RP-HPLC method for the determination of atazanavir sulphate in bulk and dosage form $[1,2]$. There are some LC-MS/MS methods were developed for the determination of genotoxic impurities in drug substances and products [3-5]. No literature was available for the determination of BOC epoxide at trace levels in atazanavir sulphate.

The international regulatory bodies from various regions have been accentuated the determination of impurities in the drug substances and drug products because of their toxicological concern [6]. The genotoxic impurities which results in genetical disorder and have the potential to cause cancer in humans, and these genotoxic impurities may be from the Starting materials, intermediates, process impurities and by-products present in the drug substances [7-9]. But it is a tough task to eliminate them completely from the synthetic scheme. Keeping in view of its significance, European Medicines Agency and ICH [ICH M7] have framed guidelines for genotoxic impurities in the drug substance $[10,11]$. These guidelines proposed a threshold limit of toxicological concern value $(1.5 \mu \mathrm{g} / \mathrm{d})$ of genotoxic impurities in the drug substances. The limit for the determination of these impurities was set based on the maximum daily dose (MDD) of the drug.
Epoxides show display carcinogenic activity when tested in rodents, with tumours often observed at the site of exposure. Epoxides are electrophilic substances, and it is likely that the carcinogenic activity of these compounds is promoted through the formation of DNA adducts [12]. Epoxides have been shown to react with DNA via an $\mathrm{SN}^{2}$ reaction to form N-7 guanosine adducts as major products, which can depurinate to give alkylated $\mathrm{N}-7$ guanine [13]. The genotoxic alert for Tert-butyl 1-(oxiran-2-yl)-2-phynyl-ethylcarbamate (BOC epoxide) was identified through DEREK nexus software [14]. LHASA predictions derived out of DEREK nexus software report clearly indicates that BOC epoxide is a very plausible entity that shows carcinogenicity, chromosome damage in vitro and mutagenicity in mammals. Though BOC epoxide is a potential known carcinogen, these data would ascertain that the regulatory authorities may expect to control the level of BOC epoxide with the limit of $3 \mathrm{ppm}$ in the drug substance (assuming $1.5 \mu \mathrm{g} / \mathrm{d}$ daily dose).

A method capable of such a lower level of detection is a great challenge for analytical method development for controlling these genotoxic impurities. Ideally conventional analytical instruments, pharmaceutical industries such as HPLC with UV detection and GC with FID detection should be employed as the standards in first attempt for PGIs analysis and these methods were discussed by Klick [15] and Volvo [16], but there are some drawbacks with the abovementioned techniques because the probability of co-elution at very trace level can change analytical results. When impurity standards are not available some method is needed to characterize the impurities online. Therefore, for accurate determination ppm levels the above-mentioned techniques are inadequate; consequently, there is a great need to develop a better analytical method for the analysis of such genotoxic impurities in pharmaceutical industries. Thus, various kinds of chromatographic techniques, methodologies have been explored as useful approaches out of Hsieh and Korfmacher [17] and Lee and Kerns [18] had discussed LC-MS/MS technique and application. 
The main objective of present research article was to develop a selective, sensitive, rapid and accurate method using LC-MS/MS technique to achieve efficient separation between atazanavir and BOC epoxide. The developed method was validated as per ICH guidelines [19] in terms of specificity, limit of detection (LOD), limit of quantification (LOQ), precision, linearity, accuracy and robustness.<smiles>COC(=O)N[C@H](C(=O)N[C@@H](Cc1ccccc1)[C@H](O)CN(Cc1ccc(-c2ccccn2)cc1)C(=O)[C@H](NC(=O)OC)C(C)(C)C)C(C)(C)C</smiles>

a). Atazanavir sulphate

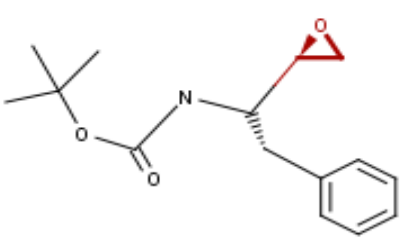

b). tert-butyl (1-(oxiran-2-yl)-2phenylethyl)carbamate (BOC epoxide)

Fig. 1: The chemical structure of Atazanavir sulphate and BOC epoxide

\section{MATERIALS AND METHODS}

\section{Chemicals and reagents}

Formic acid, ammonium hydroxide solution (25\%), methanol and acetonitrile (Merck, Mumbai, India). Purified water collected through Mill-Q plus water purification system (Millipore, Milford, MA, USA). Atazanavir sulphate and its tertbutyl 1-(oxiran-2-yl)-2phynylethylcarbamate (BOC epoxide) genotoxic impurity were synthesized from (Cipla Ltd (RandD), Bangalore, India). All the chemicals used were of LCMS Grade.

\section{Instrumentation}

The MS of LC-MS/MS system used was Applied Bio system Sciex QTRAP-5500 model, Rotkreus, Switzerland. LC was carried out on Agilent HPLC (1200 series, Germany) with photodiode array detector. As part of the experimentation, additional equipment such as PCI sonicator (22L500/CC/DTC), and precision analytical balance (MX5, Mettler Toledo, Schwerzenbach, Switzerland) was also used. Data acquisition and processing were conducted using the Analyst 1.6.2 software on a Dell computer (Digital equipment Co) system.

\section{Chromatographic conditions}

The chromatographic conditions were optimized with the analytical column Purosphere star RP 18 e, length $150 \mathrm{~mm}$, internal diameter $4.6 \mathrm{~mm}$, particle size $3.0 \mu \mathrm{m}$. The mobile phase flow was operated in isocratic mode. Eluent-A was $0.1 \%$ formic acid in water and eluent-B was $0.1 \%$ formic acid and $0.1 \%$ ammonium hydroxide solution (25\%) in acetonitrile. Eluent-B was filtered with $0.45 \mu \mathrm{m}$ to remove the haziness that occurs due to acid base addition. Eluent $A$ and eluent $B$ were kept in the separate mobile phase bottle reservoir in the ratio $30: 70(\mathrm{v} / \mathrm{v})$. The flow rate was $1.0 \mathrm{ml} / \mathrm{min}$, with the flow rate split down from 1.0 to $0.4 \mathrm{ml} / \mathrm{min}$ into the ESI MS source. The column oven temperature was maintained at $25{ }^{\circ} \mathrm{C}$ and sample cooler temperature was $10^{\circ} \mathrm{C}$. The injection volume was $10 \mu \mathrm{l}$. Positive ion electrospray ionization probe was operated with multiple reaction monitoring (MRM) detection mode for $\mathrm{m} / \mathrm{z}$ 264.1>128.9 transition for BOC epoxide and 705.4>335.3 transition for atazanavir. The declustering potential (V), entrance potential (V), collision energy $(\mathrm{V})$, collision exit potential $(\mathrm{V})$ and ion spray voltage (V) were kept as 32,12, 20, 12 and 4500 respectively. The source temperature $\left({ }^{\circ} \mathrm{C}\right)$, curtain gas flow (psi), ion source gas 1 and ion source gas 2 were maintained at $450,40,45$ and 45 respectively.

\section{Sample and standard preparation}

The test concentration of Atazanavir sulphate was derived to 10 $\mathrm{mg} / \mathrm{ml}$ based on mass detector response, where the diluent was 10.0 $\mathrm{ml}$ ammonium hydroxide solution (25\%) in $1000 \mathrm{ml}$ methanol. A white precipitation, which was formed during the sample preparation after the two minutes of sonication was filtered through $0.45 \mu \mathrm{m}$ and then injected. The standard solution of BOC epoxide was prepared with the different concentration of $0.5 \mathrm{ppm}, 1.5 \mathrm{ppm}$, $3.0 \mathrm{ppm}, 4.5 \mathrm{ppm}$ and $6.0 \mathrm{ppm}$ with respect to the test concentration.

\section{RESULTS AND DISCUSSION}

\section{Method development}

The initial trails were carried out using HPLC method with phosphate buffer, methanol and acetonitrile by gradient mode using UV detection. The attempts were failed to achieve the desired sensitivity and accuracy for the trace level of BOC epoxide ( $3 \mathrm{ppm}$ ). Hence, to obtain the sensitivity the detection technique was changed from UV to Mass. Further, the development trial with LC-MS/MS method was scrutinized with different stationary phases which included C18, C8, amino and cyano. In addition, different mobile phases such as formic acid, ammonium acetate, ammonium formate with the combination of acetonitrile and methanol have been tested for better optimisation of method.

Chromatographic separation was finally attained on a puro sphere star RP 18 e (150 mm X $4.6 \mathrm{~mm}, 3.0 \mu \mathrm{m})$ in isocratic mode using eluent-A was $0.1 \%$ formic acid in water and eluent-B was $0.1 \%$ formic acid and $0.1 \%$ ammonium hydroxide solution (25\%) in acetonitrile (eluent-A: eluent-B $(30: 70(\mathrm{v} / \mathrm{v}))$ and it was not premixed). The flow rate was $1.0 \mathrm{ml} / \mathrm{min}$, with flow rate split down from 1.0 to $0.4 \mathrm{ml} / \mathrm{min}$ into the MS source, MS parameters were set to get maximum sensitivity for the impurity of BOC epoxide.

\section{Method validation}

\section{Specificity}

Atazanavir sulphate and BOC epoxide solutions were prepared individually at a concentration of $0.5 \mathrm{ppm}$ with respect to the test concentration and a solution of atazanavir sulphate spiked with BOC epoxide was also prepared and injected. The retention time of Atazanavir and BOC epoxide was shown in table 1. Specificity chromatograms are shown in the fig. 2 to 4 .

Table 1: Determination of specificity

\begin{tabular}{lll}
\hline S. No. & Name & Retention time (min) \\
\hline 1 & Atazanavir & 1.02 \\
2 & BOC epoxide genotoxic impurity & 3.03 \\
\hline
\end{tabular}



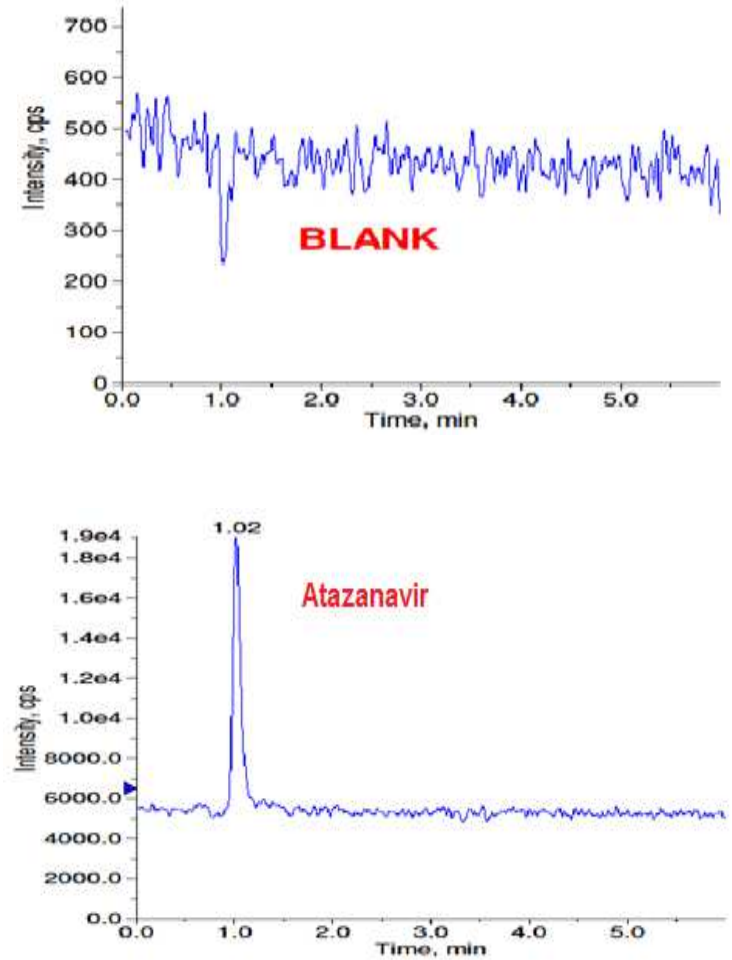

Fig. 3: Atazanavir chromatogram for specificity

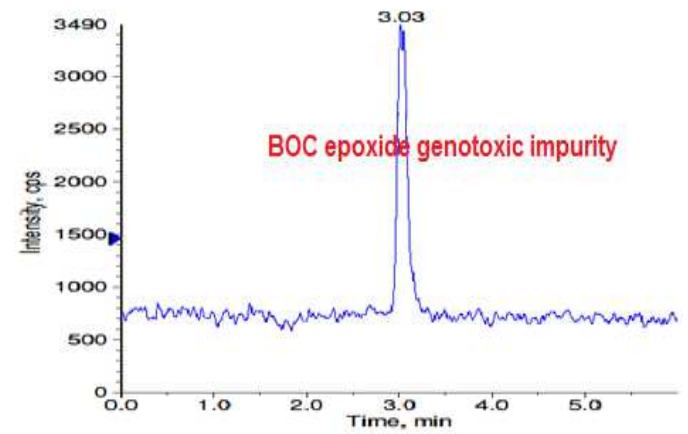

Fig. 4: BOC epoxide chromatogram for specificity

Determination of limit of detection (LOD) and limit of quantification (LOQ)

The LOD and LOQ were calculated from S/N (signal to noise) ratio. To determine LOD and LOQ values of BOC epoxide, the concentrations were reduced consecutively. The S/N ratio for LOD and LOQ for BOC epoxide was found to be 4 and 10.9 respectively. The determined LOD and LOQ were shown in fig. 5 and 6.

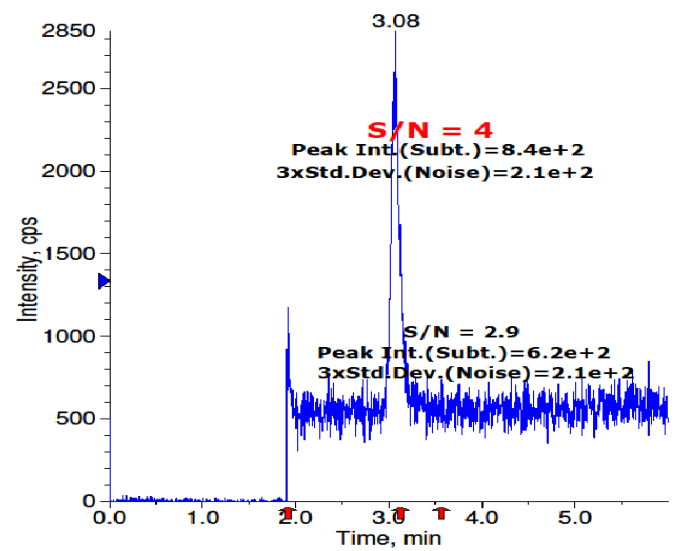

Fig. 5: LOD chromatogram of BOC epoxide

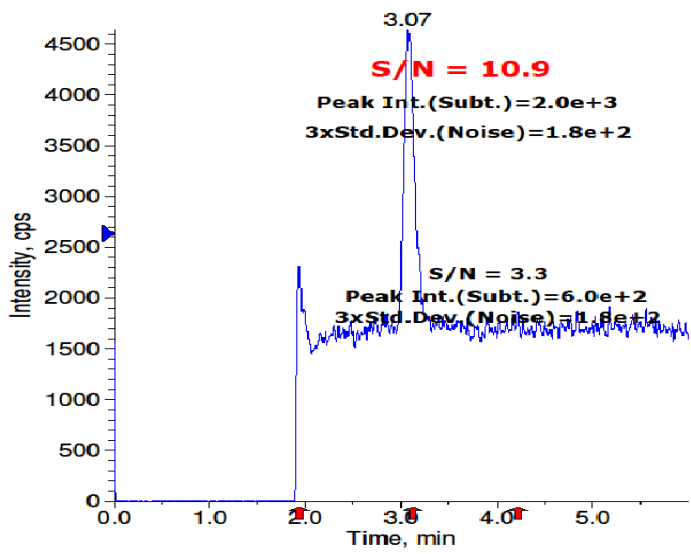

Fig. 6: LOQ chromatogram of BOC epoxide

\section{Linearity}

The linearity of the method was checked by preparing solutions at five concentration levels of $0.5 \mathrm{ppm}$ (LOQ), $1.5 \mathrm{ppm}$ (L1 solution, $50 \%$ ), $3.0 \mathrm{ppm}$ (L2 solution, 100\%), $4.5 \mathrm{ppm}$ (L3 solution, 150\%) and $6.0 \mathrm{ppm}$ (L4 solution, 200\%) for BOC epoxide. LOQ solution and L4 solution were injected in six replicates and L1, L2 and L3 solutions were injected in triplicate. Calibration curve was plotted for the peak areas (Y-axis) of BOC epoxide versus concentration (Xaxis). The correlation coefficient was found to be 0.9999 . The linearity data, graph and chromatograms for different level are shown in table 2 and fig. 7.

Table 2: Linearity $0.5 \mathrm{ppm}$ to $6.0 \mathrm{ppm}$, each level \% RSD for six and three replicate and correlation coefficient

\begin{tabular}{|c|c|c|c|c|c|c|}
\hline S. No. & \% level & Concentration (ppm) & Number of values used & Mean & Standard deviation & \%RSD \\
\hline 1 & LOQ & 0.517 & 1 of 6 & 20900.00 & 894.4 & 4.28 \\
\hline 2 & $50 \%$ & 1.550 & 1 of 3 & 63900.00 & 654.2 & 1.02 \\
\hline 3 & $100 \%$ & 3.101 & 1 of 3 & 128133.33 & 1194.4 & 0.93 \\
\hline 4 & $150 \%$ & 4.651 & 1 of 3 & 195200.00 & 1694.7 & 0.87 \\
\hline 5 & $200 \%$ & 6.201 & 1 of 6 & 262883.33 & 998.8 & 0.38 \\
\hline \multicolumn{7}{|c|}{ Slope 43972.0} \\
\hline \multicolumn{7}{|c|}{ Y-intercept-2110.0 } \\
\hline \multicolumn{7}{|c|}{ Correlation coefficient 0.9999} \\
\hline
\end{tabular}



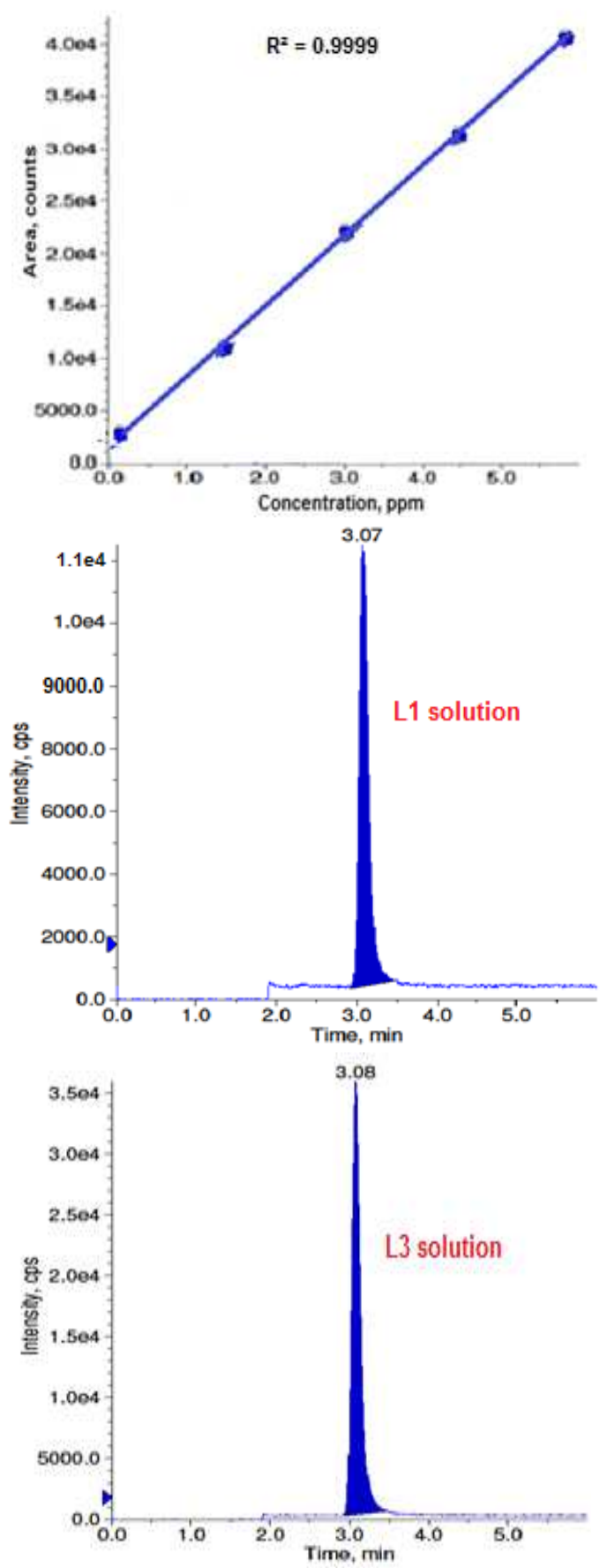
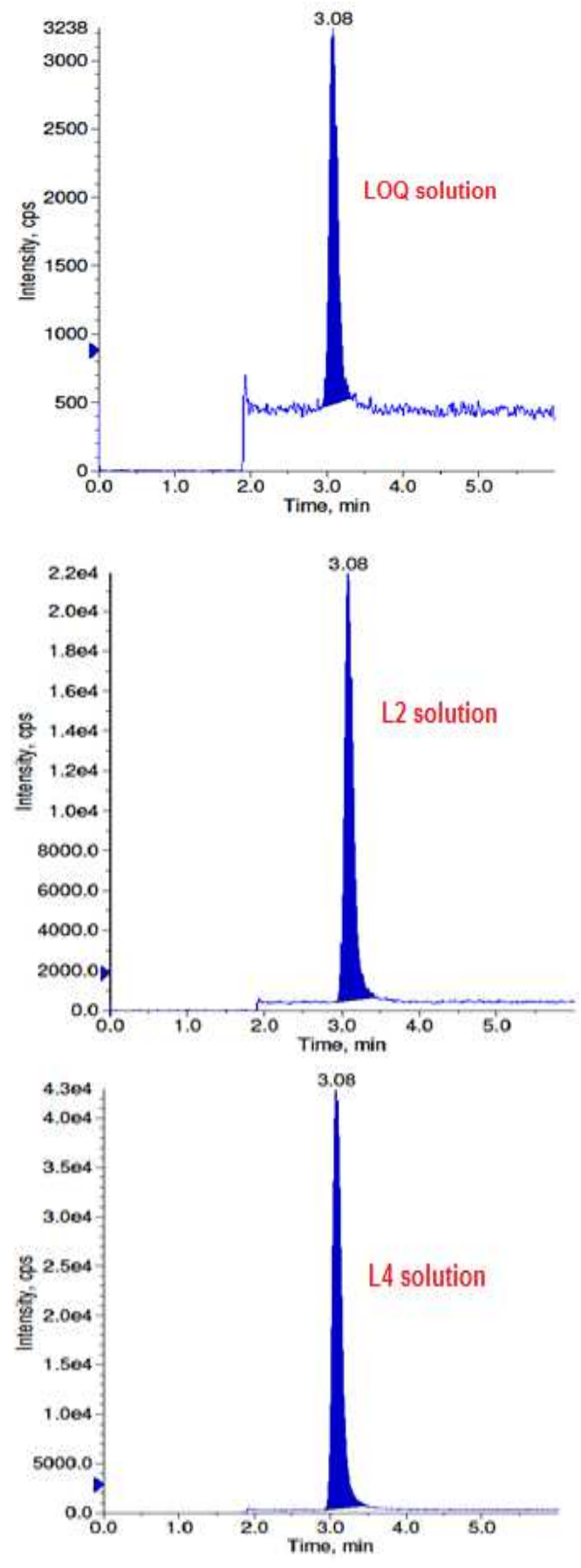

Fig. 7: Correlation coefficient and linearity $0.5 \mathrm{ppm}$ to $6.0 \mathrm{ppm}$ (LOQ solution, L1 solution, L2 solution, L3 solution and L4 solution)

\section{Accuracy}

Recovery studies by the standard addition method were performed. Accuracy was evaluated from LOQ to $200 \%$. Where the recovery was checked for LOQ level, L2 level (100\%) in six replicate injections and L1 level (50\%) and L4 level (200\%) in the triplicate injection. The recovery obtained for BOC epoxide was between $85 \%$ to $115 \%$, which indicates the method was accurate. Accuracy at LOQ chromatogram is shown in fig. 8 and \% RSD was calculated for the replicate injections of recovery at LOQ Level was shown in table 3.

\section{System, method and intermediate precision}

System precision was studied by injecting six times of BOC epoxide standard solution (3 ppm) at the limit level and the \% RSD was found to be less than $1 \%$.

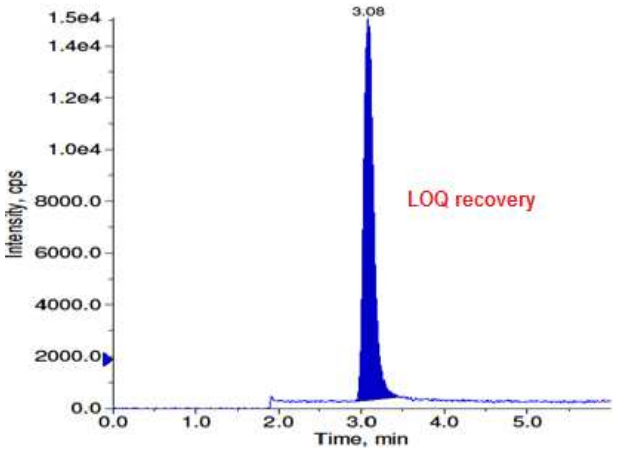

Fig. 8: Accuracy at LOQ level chromatogram 
Table 3: Accuracy for 0.5 ppm (LOQ level)

\begin{tabular}{llllll}
\hline $\begin{array}{l}\text { S. } \\
\text { No. }\end{array}$ & $\begin{array}{l}\text { Sample } \\
\text { area }\end{array}$ & $\begin{array}{l}\text { Standard } \\
\text { area }\end{array}$ & $\begin{array}{l}\text { Spiked } \\
\text { area }\end{array}$ & $\begin{array}{l}\text { Theoretical concentration } \\
\text { (mg/ml) }\end{array}$ & $\begin{array}{l}\text { Measured concentration } \\
\text { (mg/ml) }\end{array}$ \\
\hline 1 & 26146 & 20900 & 48146 & 0.000050 & 0.000051 \\
2 & 25861 & 20900 & 48998 & 0.000050 & 0.000051 \\
3 & 26110 & 20900 & 50148 & 0.000050 & 0.000051 \\
4 & 25489 & 20900 & 47314 & 0.000050 & 0.000051 \\
5 & 25969 & 20900 & 48456 & 0.000050 & 0.000051 \\
6 & 26345 & 20900 & 47946 & 0.000050 & 0.000051 \\
Average 103.9 & & & & 104.2 \\
\\
Standard deviation 0.63 \\
\%RSD 0.61
\end{tabular}

The method precision was studied by injecting the six independent solutions were $3.0 \mathrm{ppm}$ of BOC epoxide was spiked to atazanavir sulphate. The variation in the results was conveyed in terms of $\%$ RSD. The values calculated were found to be below 1\% RSD. Intermediate precision was accessed with different column, different instrument in different day. \% variation between method precision and intermediate precision studied found to be less than 10

\section{Robustness}

Robustness of the method was determined by making slight and deliberate changes in experimental conditions. The flow rate of mobile phase was altered by 0.1 units i.e. 1.0 to $1.1 \mathrm{ml} / \mathrm{min}, 1$ to 0.9 $\mathrm{ml} / \mathrm{min}$ and effect of temperature on the resolution was also studied at $23^{\circ} \mathrm{C}$ and $27^{\circ} \mathrm{C}$ (altered by 2 units). Test sample spiked with the standard at the limit level (3.0 ppm) was prepared by dissolving 100 $\mathrm{mg}$ of the test sample with a standard solution in a $10 \mathrm{ml}$ volumetric flask and injected. \% RSD found to be less than 10 in all the conditions.

\section{Stability of sample (Atazanavir sulphate) and standard (BOC epoxide) solution}

The sample solution was prepared as per the proposed method. To this sample, BOC epoxide was quantitatively spiked at limit level concentration and stored at $10{ }^{\circ} \mathrm{C}$. The spiked sample and the standard solution limit level $(3 \mathrm{ppm})$ were injected into the system immediately and at various intervals. The \% relative difference between method precision and solution stability study were calculated and found below 10. This indicated that the sample solution and standard solution were found to be stable up to $48 \mathrm{~h}$ at $10{ }^{\circ} \mathrm{C}$.

Therefore, the proposed method is capable to establish specificity, LOD, LOQ and accuracy as per ICH guidelines. In addition to this, the method was successfully used to determine the BOC epoxide content in drug substance during API batch manufacture for quality control release.

\section{CONCLUSION}

The results of the present study indicated that the newly developed LC-MS/MS analytical method used for determination of BOC epoxide content in atazanavir sulphate complies with the acceptance criteria for the analytical parameters such as specificity, limit of detection, limit of quantification, precision: a) system precision b) Repeatability and c) intermediate precision, linearity and range, accuracy, solution stability and robustness. Hence method stands validated. The LOD and LOQ of the developed method were quite satisfactory. In addition to this method can be employed conveniently, consistency and successfully for the estimation of BOC epoxide for routine quality control and stability studies in drugs and pharmaceuticals.

\section{ACKNOWLEDGEMENT}

The authors are grateful to the management of Cipla Limited, Department of chemistry, S. R. N. B. Degree and P. G. College and Department of Chemistry, JNTUA college of Engineering, Anantapur for their support, encouragement to carry out research work. Also, the authors would like to express their special thanks to Analytical
RandD Head Dr Manish Gangrade and Dr J Jayachandran, who have supported this project throughout this study.

\section{CONFLICT OF INTERESTS}

\section{Declared none}

\section{REFERENCES}

1. Chitturi SR, Somannavar YS, Peruri BG, Nallapati S, Sharma HK, Budidet SR, et al. Gradient RP-HPLC method for the determination of potential impurities in atazanavir sulphate. J Pharm Biomed Anal 2011;55:31-47.

2. Bhirud CH, Hiremath SN. Stability indicating RP-HPLC method for the determination of atazanavir sulphate in bulk and dosage form. Drug Invent Today 2013;5:81-6.

3. Bhavani KG, Krishna KBM, Srinivasu N, Ramachandran D. Determination of genotoxic impurity in atazanavir sulphate drug substance by LC-MS. J Pharm Biomed Anal 2017;132:156-8.

4. Balaji N, Sultana S. Ultra-high performance liquid chromatographic determination of genotoxic impurities in febuxostat drug substance and products. Asian J Pharm Clin Res 2017;10:324-30.

5. Natarajan S, Kempegowda BK, Bharathiar M. Determination of traceable genotoxic impurity cholroacetyl chloride a carcinogen by LC/MS/MS in drug substances. Asian J Pharm Clin Res 2016;9:97-100.

6. International conference on Harmonisation Q3A-Q3D Impurities-International Council for Harmonization guidelines; 2006. p. 1-11.

7. Bolt HM, Foth H, Hengstler JG, Degen GH. Carcinogenicity categorization of chemicals-new aspects to be considered in a European perspective. Toxicol Lett 2004;151:29-41.

8. Müller L, Mauthe RJ, Riley CM, Andino MM, De Antonis D, Beels $\mathrm{C}$, et al. A rationale for determining, testing, and controlling specific impurities in pharmaceuticals that possess potential for genotoxicity. Regul Toxicol Pharmacol 2006;44:198-211.

9. Jacobson-Kram D, McGovern T. Toxicological overview of impurities in pharmaceutical products. Adv Drug Delivery Rev 2007;59:38-42.

10. Guideline on the limits of genotoxic impurities, EMA guidance MEA/CHMP/QWP/251344; 2006.

11. Guideline for Assessment and Control of DNA Reactive (Mutagenic) Impurities in pharmaceuticals to Limit Potential Carcinogenic risk, M7 ICH; 2014.

12. Dipple A. DNA adducts of chemical carcinogens. Carcinogenesis 1995;16:437-41.

13. Koskinen M, Plna K. Specific DNA adducts induced by some mono-substitued epoxides in vitro and in vivo. Chem Biol Interact 2000;129:209-29.

14. Deductive Estimation of Risk from Existing Knowledge (DEREK) nexus, marketed by LHASA Ltd, Leeds, Yorkshire, U. K, DEREK nexus program Version Derek Nexus: 3.0.1, Nexus: 1.5.1; 2017.

15. Klick S. Evaluation of different injection techniques in the gas chromatographic determination of thermolabile trace impurities in a drug substance. J Chromatogr A 1995; 689:69-76. 
16. Valvo L, Alimenti R, Alimonti S, Raimondi S, Foglietta F, Campana F, Development and validation of a liquid chromatographic method for the determination of related substances in verapamil hydrochloride. J Pharm Biomed Anal 1997;15:989-96.

17. Hsieh Y, A Korfmacher W. Increasing speed and throughput when using HPLC-MS/MS systems for drug metabolism and pharmacokinetic screening. Curr Drug Metab 2006;7:479-89.

18. Lee MS, Kerns EH. LC/MS applications in drug development. Mass Spectrom Rev 1999;18:187-279.
19. Guidelines for Validation of Analytical Procedures, Q2 (R1), ICH; 1994.

\section{How to cite this article}

- Nelaturi Subbaiah, Gopireddy Venkata Subba Reddy. A selective and sensitive method development and validation by LC-MS/MS approach for trace level quantification of potential genotoxic impurity of boc epoxide in atazanavir sulphate drug substance. Int J Pharm Pharm Sci 2017;9(9):143-148. 